A N N A L E S Annales de Bretagne et des Pays de l'Ouest

Anjou. Maine. Poitou-Charente. Touraine

118-4 | 2011

Varia

\title{
Le kersanton, une pierre bretonne
}

Daniel Tanguy

\section{OpenEdition}

Journals

Édition électronique

URL : http://journals.openedition.org/abpo/2187

DOI : $10.4000 /$ abpo. 2187

ISBN : 978-2-7535-1841-4

ISSN : 2108-6443

Éditeur

Presses universitaires de Rennes

Édition imprimée

Date de publication : 30 décembre 2011

Pagination : 131-132

ISBN : 978-2-7535-1839-1

ISSN : 0399-0826

Référence électronique

Daniel Tanguy, "Le kersanton, une pierre bretonne », Annales de Bretagne et des Pays de l'Ouest [En ligne], 118-4 | 2011, mis en ligne le 30 décembre 2011, consulté le 23 septembre 2020. URL : http:// journals.openedition.org/abpo/2187 ; DOI : https://doi.org/10.4000/abpo.2187

Ce document a été généré automatiquement le 23 septembre 2020.

(c) Presses universitaires de Rennes 


\title{
Le kersanton, une pierre bretonne
}

\author{
Daniel Tanguy
}

\section{RÉFÉRENCE}

CHAURIS, Louis, Le kersanton, une pierre bretonne, Rennes/Quimper, PUR/Société

archéologique du Finistère, 2010, 242 p. (ISBN 978-2-7535-1162-0).

1 Louis Chauris est à la fois un savant géologue et un érudit historien. Depuis de nombreuses années, il a multiplié dans les revues des articles sur un thème dont il s'est fait une spécialité : l'étude des monuments - et plus généralement des constructions, aussi bien religieuses, civiles que militaires - non plus seulement en considération de leurs formes architecturales, mais en fonction du matériau de construction, à savoir, avant l'arrivée du béton, la pierre. Géologue, l'auteur a une connaissance approfondie des roches bretonnes et spécialement finistériennes, qui lui permet de localiser l'origine des pierres qui ont servi à l'édification des églises, chapelles, maisons, châteaux, ports, etc., connaissance de terrain qu'il complète par des recherches dans les archives, d'où il exhume rapports d'ingénieurs et d'architectes, devis d'entrepreneurs, factures, feuilles de paie, etc. Le résultat est prodigieusement intéressant, car il porte un regard nouveau sur l'histoire de l'art breton, et notamment sur l'architecture et la sculpture, mais aussi sur l'histoire, bien méconnue, des travaux publics aux $\mathrm{XIX}^{\mathrm{e}}$ et $\mathrm{Xx}^{\mathrm{e}}$ siècles. Bien entendu, le cadre de l'étude est essentiellement finistérien.

2 L'idée de regrouper toutes les connaissances sur l'un de ces matériaux, l'un des plus mythiques, pourrait-on dire, de Basse-Bretagne, le kersanton - ou, pour les géologues, la kersantite - a donné naissance à cette synthèse, publiée conjointement par les Presses universitaires de Rennes et la Société archéologique du Finistère, dont L. Chauris est l'un des membres les plus éminents. La matière de l'ouvrage est présentée en vingt et un chapitres précédés d'un avant-propos et conclus par un index. L'illustration est abondante, et la cartographie remarquable. 
3 Tout d'abord, l'auteur tord le cou à diverses erreurs communément répandues sur le kersanton. Celui-ci serait un matériau granitique ou volcanique : faux ! c'est une roche magmatique, filonienne, appartenant au groupe des lamprophyres, "qui n'a guère de points communs avec le granite» (p. 7). Le kersanton est inaltérable : faux encore! le kersanton extrait des carrières du village de Kerzanton en Loperhet est sujet à la desquamation, celui de Rosmorduc en Logonna résiste parfaitement à l'épreuve du temps. Le kersanton n'existe qu'au fond de la rade de Brest : faux toujours! on trouve de la kersantite dans diverses régions du monde, et, en Bretagne même, sous forme de filons, dans le bassin de Châteaulin, aux environs de Lennon, de Châteauneuf-du-Faou, de Poullaouen, de Carhaix.

Ces précisions apportées, l'auteur recherche - sans pouvoir apporter de réponse définitive - «à quand remonte l'emploi en grand du kersanton » (p. 21) (après avoir évoqué rapidement une brève utilisation pour des stèles de l'âge du fer) : c'est peut-être à l'abbaye de Landévennec vers la fin du XI $\mathrm{I}^{\mathrm{e}}$ ou au début du XII ${ }^{\mathrm{e}}$ siècle (et non, comme on l'a cru longtemps, au cloître de l'abbaye de Daoulas, construit en microgranite du Roz, dans la seconde moitié du XII ${ }^{e}$ siècle), au château de Brest au XIII siècle, ou à l'« arc de triomphe » de l'église de La Martyre, au milieu du XIVe siècle, mais rien n'est assuré. Il semble donc que le kersanton a commencé à être utilisé en divers lieux comme matériau de construction, mais c'est l'édification, au $\mathrm{xv}^{\mathrm{e}}$ siècle, de la collégiale du Folgoët, qui a fait un très large appel à cette pierre. Et l'on notera que, curieusement, la ville de Nantes a acquis 1800 boulets en kersanton, en 1474, mais on est loin, là, d'une utilisation à grande échelle dans la construction d'édifices religieux ou dans la sculpture...

5 Six chapitres sont ensuite consacrés à la géologie du kersanton de la rade de Brest, aux problèmes de son altération après sa mise en œuvre, aux sites d'extraction, aux accumulations de déblais sur l'estran, au transport de la production des carrières (par mer, mais aussi par voie ferrée), jusqu'aux Sables-d'Olonne et même à Marseille !

6 L'emploi du kersanton est surtout connu dans le domaine de l'art religieux. L. Chauris évoque les sculpteurs qui, depuis Bastien et Henry Prigent au Xvi ${ }^{\mathrm{e}}$ siècle, Roland Doré au $\mathrm{XVII}^{\mathrm{e}}$, ont travaillé ce remarquable matériau, entre autres Yves Hernot et Yan Larhantec $\mathrm{au} \mathrm{XIX}^{\mathrm{e}}$ siècle, René Quillivic au $\mathrm{xx}^{\mathrm{e}}$. Un long chapitre est consacré aux églises et chapelles ayant été construites, totalement ou en partie, en kersanton. L'inventaire qui est donné n'est pas exhaustif - l'auteur n'a pas cette prétention -, mais est déjà impressionnant, alors que sont passés volontairement sous silence les croix et calvaires qui sont trop nombreux pour entrer dans le cadre de l'ouvrage.

7 Les chapitres les plus nouveaux sont consacrés à des formes d'utilisation du kersanton qui ont été peu étudiées jusqu'à présent : l'art funéraire (les tombes, les monuments commémoratifs, les monuments aux morts), les constructions civiles (châteaux et manoirs, maisons de villes ou de la campagne, écoles, mairies, etc.), le canal de Nantes à Brest, les routes, les ponts, les ports, les phares, les forts militaires... Rien n'échappe à l'œil vigilant de l'auteur !

Des roches, proches par leur aspect, du kersanton du fond de la rade de Brest, et/ou qui lui ont souvent été associées dans les constructions, font l'objet de développements utiles. Ainsi le kersanton du bassin de Châteaulin, la pierre de Logonna, les diorites du Léon, ou de Lanvellec en Trégor, ou de Plélauff en Vannetais, offrent souvent des points communs avec le kersanton de la rade de Brest, et les confusions sont fréquentes. 
9 L'ouvrage se clôt sur une touche nostalgique. Après avoir rappelé la «destinée exceptionnelle » (p. 223) du kersanton, depuis l'âge du fer (quelques stèles) jusqu'au milieu $\mathrm{du} \mathrm{xx}^{\mathrm{e}}$ siècle, et les raisons de sa désaffection (aspect noirâtre, concurrence du granite rose de l'Aber-Ildut ou Laber ou même de granites en provenance d'Inde ou du Brésil, «emprise irrésistible du béton» [p.224], situation reculée des carrières), L. Chauris pose la question : "Quel avenir pour le kersanton?» (p. 223), à la suite de son abandon après la Seconde Guerre mondiale ? Diverses possibilités sont évoquées : utilisation dans la restauration des monuments historiques, préservation et valorisation d'un ou deux sites d'extraction, renouveau de la sculpture... On ne peut que souhaiter avec l'auteur que, grâce à « l'impact culturel, voire sentimental, qui s'attache toujours à cette pierre [...], elle retrouve - au XxI ${ }^{\mathrm{e}}$ siècle - un regain de jeunesse, à l'image même de la Bretagne, aujourd'hui résolument ouverte sur l'avenir » (p. 229).

Daniel TANGUY 